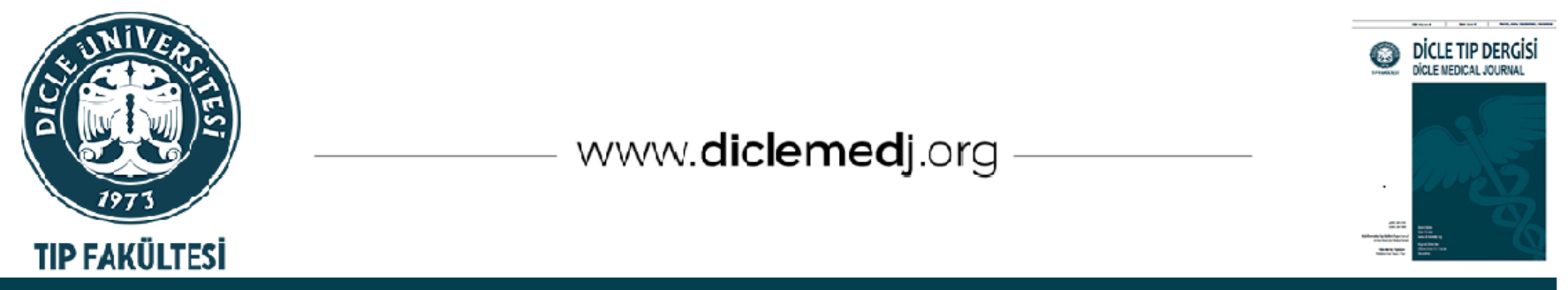

Original Article / Özgün Araştırma

\title{
Youtube Contents Provides Inadequate Information About The Diagnosis And Treatment of Hallux Valgus
}

\author{
Adem Sahin ${ }^{1}$, Anıl Agar ${ }^{1}$ \\ 1 Consultant Orthopaedic Surgeon. Saglik Bilimleri University, Kanuni Sultan Suleyman training and research hospital, \\ Orthopaedic and Traumatology Department, Kucukcekmece/Istanbul, Turkey
}

Received: 09.05.2021; Revised: 16.06.2021; Accepted: 06.07.2021

\begin{abstract}
Objective: According to the data in September 2020,63.2\% of the world population uses the internet. Internet is one of the most important sources for fast and easy access to information. Youtube is the second most popular social media network platform. Our aim in this descriptive study was to evaluate the accuracy and quality of the information in hallux valgus videos shared on YouTube.

Methods: The keywords "hallux valgus" and "bunyon" were searched on Youtube respectively. The videos were evaluated by two independent reviewers according to VPI, Discern, GQS, JAMA and HVS scoring systems.

Results: As a result of search a total of 64 videos were evaluated. The view count varies between 56438 and 14799537 , with a mean of $665114.48 \pm 1837230.87$. The videos had a total run time varies between 47 and 3731 seconds, with a mean of $457.67 \pm 538.93$ seconds. The average; VPI score was $1336,77 \pm 8212,91$; Discern score was 1,55 $\pm 0,58$; GQS score was 2,17 $\pm 0,83$; JAMA score was 1,39 $\pm 0,48$ and HVS score was 4,72 $\pm 4,83$.
\end{abstract}

Conclusion: Information on the diagnosis and treatment of hallux valgus on Youtube is of low quality and its content is of unknown source and accuracy.

Keywords: Youtube, hallux valgus, bunion, quality, treatment

DOI: 10.5798/dicletip.987898

Correspondence / Yazışma Adresi: Adem Sahin, Saglik Bilimleri University, Kanuni Sultan Suleyman training and research hospital, Orthopaedic and Traumatology Department, Atakent mah, Istanbul cad. No:1, 34303, Kucukcekmece, Istanbul,Turkey e-mail: ademtito@yahoo.com 


\section{Youtube İçerikleri Halluks Valgus'un Tanı ve Tedavisi Hakkında Yetersiz Bilgi Sağlıyor Öz}

Amaç: Eylül 2020 verilerine göre dünya nüfusunun\% 63,2'si internet kullanmaktadır. İnternet, bilgiye hızlı ve kolay erişim için en önemli kaynaklardan biridir. Youtube, en popüler ikinci sosyal medya ağı platformudur. Bu tanımlayıcı çalışmada amacımız, YouTube'da paylaşılan halluks valgus videolarındaki bilgilerin doğruluğunu ve kalitesini değerlendirmektir.

Yöntemler: Youtube'da sırasıyla "hallux valgus" ve "bunyon bunion" anahtar kelimeleri arandı. Videolar VPI, Discern, GQS, JAMA ve HVS puanlama sistemlerine göre iki bağımsız yorumcu tarafından değerlendirildi.

Sonuçlar: Arama sonucunda toplam 64 video değerlendirildi. Görüntüleme sayısı, ortalama $665114,48 \pm 1837230,87$ ile 56438 ile 14799537 arasında değişmektedir. Videoların süresi 47 ile 3731 saniye arasında değişmekte olup, ortalama 457,67 \pm 538,93 saniyedir. Ortalama; VPI puanı 1336,77 \pm 8212,91; Discern puanı 1,55 $\pm 0,58$; GQS puanı 2,17 $\pm 0,83$; JAMA puanı $1,39 \pm 0,48$ ve HVS puanı $4,72 \pm 4,83$ idi.

Sonuç: Youtube'da halluks valgus tanı ve tedavisi ile ilgili bilgiler düşük kalitededir ve içeriği bilinmeyen kaynak ve doğruluktadır.

Anahtar kelimeler: Youtube, halluks valgus, bunion, kalite, tedavi.

\section{INTRODUCTION}

The internet is one of the common resources for information related to health. Over $61 \%$ of Americans seek diagnostic, therapeutic and prognostic insights online for their various ailments. According to data collected on 30 September 2020, $63.2 \%$ of the world's population uses the internet. The rate of internet usage has increased by $1,266 \%$ between 2000 and $2020^{1}$. With the increase in internet use, studies examining its effect on people have also increased ${ }^{2}$. For people between the ages of 18 and 29, the usage rate of social media increased by approximately $90 \%$ during the same period ${ }^{3}$. Today, YouTube is the second most frequently used social media platform, a global social network used in 88 countries and translated into 76 languages with more than one billion users ${ }^{4}$. With more than 300 video uploads per minute and 100 million hours of viewing per day, YouTube is growing incredibly fast ${ }^{4}$. Since its inception in 2005, it has become readily accessible and userfriendly, growing to the third most popular website globally, with more than 2 million page views per day5. In the US, $80 \%$ of people between the ages of 14 and 29 use YouTube; for those between the ages of 18 and 49 , the rate is $90 \%{ }^{3,4}$.

YouTube enables different modes of information to be presented by goying going beyond the usual details based on text to enhance the lay understanding of health. Consequently, these characteristics make YouTube a probably profitable source of dissemination and sharing of healthcare information. Nevertheless, due to the limited evaluation of some information's quality and reliability, the risk of spreading inaccurate information should be considered ${ }^{6}$. Therefore, it is essential to determine the accuracy and quality of the content of videos related to health published on YouTube.

The accuracy and quality of videos about patient education have been recently interesting around the world. For most patients, information related to health on the internet is better than or equal to physicians' knowledge. Many patients using the internet as an information source fail to report their search results to their physicians 7 . Patients' online reading and information gathering might affect their perception of their diagnosis and their treatment outcomes expectations. Content on 
YouTube is not subject to peer review and, therefore, the information quality is not known. There is a risk that information on YouTube might harm patient-clinician interactions. Therefore, investigating this content is crucial for physicians ${ }^{8}$.

Hallux valgus is the most common foot deformity affecting the big toe and is one of the most common causes of outpatient clinic admissions for foot disorders 9 ,10. Hallux valgus deformity is due to a medial deviation of the first lateral and metatarsal deviation of the big toe, using or not using subluxation of the same joint, along with pronation of the metatarsophalangeal joint. The aetiology etiology of the deformity is complex and multifactorial, consisting of internal and external risk factors. Furthermore, this condition influences $23 \%$ of the adult population ${ }^{11,12}$.

This descriptive study was conducted to characterise characterize the quality and content of information about hallux valgus available on YouTube. Our aim was to analyse analyze the audience response and interaction with videos presented by this mass medium.

\section{METHODS}

The YouTube search engine (https://www.youtube.com) was searched separately for the keywords 'hallux valgus' and 'bunion' on 23 November 2020. The standard YouTube search setting of "view count" was used to rate the most-watched and used videos. Search results were limited to the first three pages of results given that users do not look beyond the third page of results about video information. Studies have shown that below $17 \%$ of the internet users see results beyond the first three pages of search results ${ }^{13}$.

Videos were excluded if they were non-English or were not related to hallux valgus. Duplicate videos with no accompanying audio were also excluded. The running time, the number of comments, time since upload, the number of views/day, the number of views, the like ratio, and the number of likes and dislikes (like*100/[like+dislike]) were specified. Because the literature was inconclusive for an index that evaluates both views and similar video viewing rates, we chose to assess the videos' popularity using an index called Video Power Index (VPI) which was calculated using the following formula: like ratio * view ratio / 100.

The quality of the provided information was assessed with four tools:

1. The modified Discern score, defined by Singh et al. ${ }^{14}$

2. The Global Quality Score (GQS) ${ }^{15}$

3. The JAMA benchmark ${ }^{16}$

4. The Hallux Valgus Specific Score (HVS) ${ }^{17}$

The written health information was evaluated by developing the Discern score at Oxford University, the United Kingdom. It initially consisted of 16 questions. Each question is scored from 1 to 5 . The minimum score was six, and the maximum score is $80^{18}$. Singh et al. evaluated YouTube by modifing modifying DISCERN. Scoring for clarity, bias/balance, reliability, additional information provision, and uncertainty criteria were established ${ }^{14}$.

The Global Quality Score (GQS) uses a 5-point scale to rank the video's overall quality based on the quality of the information and the usefulness of the particular video for a patient as the reviewer thought ${ }^{15}$. The GQS was discussed and evaluated among the observers, and a decision was made on a standard score.

The JAMA benchmark evaluates online information quality based on four criteria (attribution, description, authorship, and currency) ${ }^{16}$. 1) Authorship includes details about contributors or authors be provided on the website, along with their credentials and links. 2) Attribution requires that all content references and sources be identified, along with 
all related copyright information. 3) Disclosure needs specific and complete disclosure of website ownership, including financial and commercial ties and probable conflicts of interest. 4) Currency ensures dating of content during the initial upload and on subsequent updates. A score is awarded based on each of the met criteria, getting the scores ranging from 0 to 4 , and 4 indicates better quality.

For this study, all videos were assessed by two independent observers with the grading system described by Tartaglione et al. to evaluate the accuracy, readability, and quality of online resources about Hallux Valgus. All videos were scored independently ${ }^{17}$. There were 25 items in a quality grading sheet with the elements of diagnosis, treatment plan, anatomy, and complications for the hallux valgus (Figure 1). The quality of each website which was included in the study was evaluated by the reviewers. The two reviewers' quality scores were combined and averaged, leading to a mean quality score (at most 25 points) for each website. Consensus discussion was made to clarify discrepancies of the categories. The videos were evaluated using seven criteria for source and five standards for content.

Source-based categories included 1) physician (author or authors were group or individual physicians with no research or university group), 2) academic (authors or author affiliated with a research or university group), 3) non-physician (allied physiotherapists, health professionals, chiropractors, alternative medical providers, and occupational therapists), 4) medical (websites related to health), 5) trainer, 6) patient, and 7) commercial.

Content-based categories were 1) information about the disease, 2) surgical technique, 3) exercise training, 4) chiropractic treatment, and 5) advertisement.

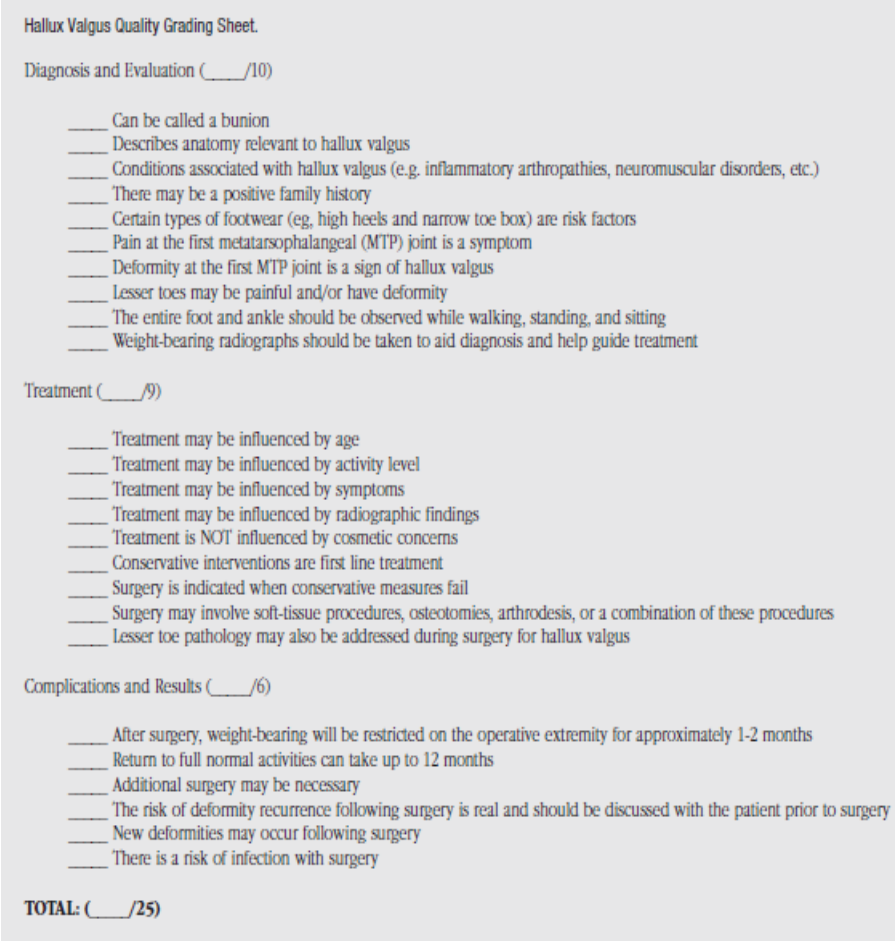

Figure 1: Hallux valgus quality assessment scale described by Tartaglione et al.(16)

\section{Statistical Analysis}

When the study findings were evaluated, IBM SPSS Statistics 22 for statistical analysis (SPSS IBM, Turkey) was used. To evaluate the study data, suitability of the parameters to the normal distribution was assessed with the Shapiro Wilks test. Besides the descriptive statistical methods (standard deviation, mean, frequency), the parameters not showing a normal distribution in the quantitative data were compared using the Kruskal Wallis test. Dunn's test was used to identify the group causing the difference. Spearman's rank correlation coefficient analysis was used to investigate the relationships between parameters not conforming to normal distribution. To determine the level of observer agreement, the

intraclass correlation coefficient (ICC), lower and upper limits were calculated. $p<0.05$ level was statistically significant.

\section{RESULTS}

After the videos meeting the exclusion criteria were removed, 64 videos were evaluated for the 
study. The values examined in the study parameters and the video distribution by year are shown in Table 1 . The sources of the videos include $26.6 \%$ non-physician, $26.6 \%$ physician, $21.9 \%$ medical, $12.5 \%$ academic, $6.3 \%$ commercial, $4.7 \%$ trainer and $1.6 \%$ patient (Figure 2). The contents of the videos represented $29.7 \%$ exercise, $28.1 \%$ surgical, $21.9 \%$ disease information, $14.1 \%$ chiropractor and $6.3 \%$ advertisements (Figure 3).

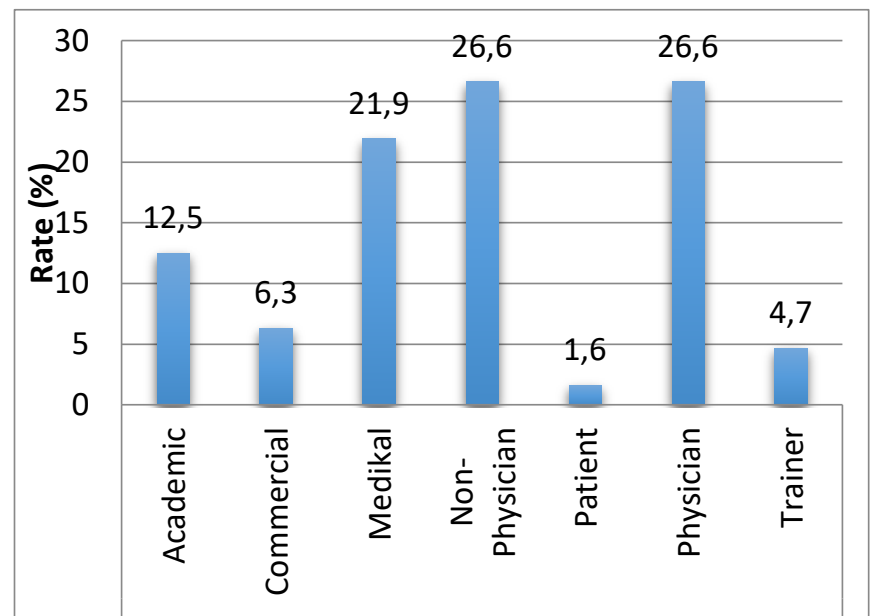

Figure 2: Categorical distribution of the videos based on source.

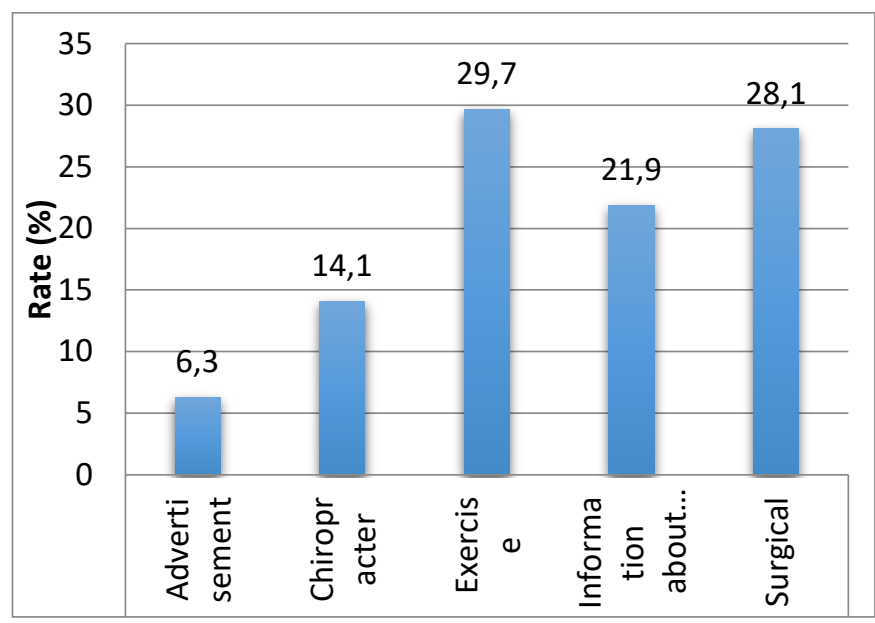

Figure 3: Categorical distribution of the videos based on content.

The highest number of uploads occurred in 2017, an upload rate was $15.6 \%$, while the lowest number of uploaded videos was in 2008 and 2020, each with an upload rate of $1.6 \%$ (Table 1 ).
Table I: Minimum, maximum, mean, standard deviation and median $\mathrm{n}$ and percentage values for study parameters

\begin{tabular}{|c|c|c|c|}
\hline & Min-Max & Mean \pm SD & Median \\
\hline GQS & $1-4$ & $2,17 \pm 0,83$ & 2 \\
\hline HVS & $1-20$ & $4,72 \pm 4,83$ & 2 \\
\hline Time & $47-3731$ & $457,67 \pm 538,93$ & 316 \\
\hline Like & $53-164418$ & $5278,27 \pm 20566,24$ & 1543,5 \\
\hline Dislike & $3-5766$ & $295,23 \pm 740,97$ & 115,5 \\
\hline Like ratio & $72,1-97,8$ & $90,5 \pm 6,18$ & 92,2 \\
\hline $\begin{array}{l}\text { Number of } \\
\text { comments }\end{array}$ & $0-8480$ & $284,77 \pm 1056,02$ & 101,5 \\
\hline $\begin{array}{l}\text { Number of } \\
\text { views }\end{array}$ & $56438-14799537$ & $665114,48 \pm 1837230,87$ & 293504,4 \\
\hline View ratio & $17,3-68200,7$ & $1400,36 \pm 8501,58$ & 182,3 \\
\hline VPI & $15,3-65881$ & $1336,77 \pm 8212,91$ & 159 \\
\hline \multicolumn{4}{|l|}{ Year $_{n, \%}$} \\
\hline 2008 & 1 & 1,6 & \\
\hline 2009 & 2 & 3,1 & \\
\hline 2010 & 3 & 4,7 & \\
\hline 2011 & 3 & 4,7 & \\
\hline 2012 & 8 & 12,5 & \\
\hline 2013 & 4 & 6,3 & \\
\hline 2014 & 8 & 12,5 & \\
\hline 2015 & 4 & 6,3 & \\
\hline 2016 & 7 & 10,9 & \\
\hline 2017 & 10 & 15,6 & \\
\hline 2018 & 8 & 12,5 & \\
\hline 2019 & 5 & 7,8 & \\
\hline 2020 & 1 & 1,6 & \\
\hline
\end{tabular}


VPI scores ranged from 15.3 to 65,881 , with a mean of $1,336.77 \pm 8,212.91$ and a median of 159. No statistically significant difference was found between the VPI scores related to source (p> 0.05) (Table 4). A statistically significant difference was between the VPI scores in terms of the content (p: 0.001; $<$ <0.05) (Table 5). As a result of post hoc evaluations made to determine the contents from which the significance originates, the VPI score for surgical content was significantly lower than those for disease information and exercise (p1: 0.016; p2: 0.001; p <0.05). No significant difference was among the other contents in the VPI scores ( $p>0.05)$.

For the first observer, the Discern score varied between 1 and 4, with a mean of $1.5 \pm 0.55$ and a median of 1.3. For the second observer, the Discern score ranged between 1 and 4, with a mean of $1.6 \pm 0.62$ and a median of 1.4. The average Discern score was $1.55 \pm 0.58$, and the median was 1.35 (Table 2). No video gained a score above 4 out of a possible 5 . The level of agreement between the two observers was 96.1\% (Table 3). A statistically significant difference was found between the sources in the Discern scores (p: 0.031; p <0.05) (Table 4). As a result of the post hoc evaluations made to determine the sources of significance, the Discern score of the non-physician source was significantly lower than the physician and medical sources (p1: 0.004; $\mathrm{p} 2$ : 0.036; $\mathrm{p}<0.05$ ). No significant difference was between other Discern scores ( $p>0.05)$. Although the Discern scores were close to significance between contents, there was no statistically significant difference ( $p>0.05$ ) (Table 5). Although the difference was not substantial, it was striking that the average Discern score for disease information was higher than those for other content.
Table II: Minimum, maximum, mean, standard deviation and median values of Discern and JAMA scores

\begin{tabular}{|llll|}
\hline & Min-Max & Mean \pm SD & Median \\
\hline \hline Discern reviewer 1 & $1-4$ & $1,5 \pm 0,55$ & 1,3 \\
Discern reviewer 2 & $1-4$ & $1,6 \pm 0,62$ & 1,4 \\
Discern score & $1-4$ & $1,55 \pm 0,58$ & 1,35 \\
JAMA reviewer 1 & $1-3$ & $1,34 \pm 0,54$ & 1 \\
JAMA reviewer 2 & $1-3$ & $1,44 \pm 0,56$ & 1 \\
JAMA score & $1-3$ & $1,39 \pm 0,48$ & 1,5 \\
& & & \\
\hline
\end{tabular}

Table III: Level of agreement of inter-observer Discern and JAMA scores

\begin{tabular}{|lllll|} 
& & \multicolumn{2}{c}{$\% 95$ CI } & \\
\cline { 3 - 4 } & ICC & Lower & Upper & p \\
& & & & \\
\hline \hline Discern score & 0,961 & 0,937 & 0,976 & $0,000^{*}$ \\
JAMA score & 0,791 & 0,638 & 0,853 & $0,000^{*}$ \\
& & & & \\
\hline
\end{tabular}

GQS scores varied between 1 and 4, with an average of $2.17 \pm 0.83$ and a median of 2 . A statistically significant difference was found between the GQS scores for the source (p: 0.021; $\mathrm{p}<0.05$ ) (Table 4). As a result of the post hoc evaluations to determine the sources of significance, the GQS score for commercial source was significantly lower than those for the academic, medical and physician sources (p1: 0.026; p2: 0.043; p3: 0.030; p <0.05). The GQS score for the non-physician source was significantly lower than those for academic, medical, and physician sources (p1: 0.022; p2: 0.033; p3: 0.016; p <0.05). No significant difference was found between the GQS scores for other sources ( $p>0.05)$. 
Table IV: Evaluation of scores by source

\begin{tabular}{|c|c|c|c|c|c|}
\hline \multirow{4}{*}{ Source } & Discern & JAMA & GQS & HVS & VPI \\
\hline & \multicolumn{4}{|c|}{ Mean $\pm S D($ medi } & \multirow{3}{*}{$\begin{array}{l}\text { Mean } \pm \text { SD } \\
\text { (median) }\end{array}$} \\
\hline & \multirow[t]{2}{*}{ Mean $\pm D$ (media) } & Mean SD (median) & & Mean \pm SD (median) & \\
\hline & & & an) & & \\
\hline Academic & $1,63 \pm 0,48(1,4)$ & $1,5 \pm 0,38(1,5)$ & $2,63 \pm 0,92(2)$ & $7,75 \pm 7,72(3,5)$ & $214,6 \pm 174,32(170,1)$ \\
\hline Commercial & $1,26 \pm 0,16(1,2)$ & $1,63 \pm 0,48(1,8)$ & $1,5 \pm 0,58(1,5)$ & $3,75 \pm 2,75(3,5)$ & $89,43 \pm 30,58(84,9)$ \\
\hline Medical & $1,76 \pm 0,64(1,5)$ & $1,36 \pm 0,57(1)$ & $2,36 \pm 0,74(2)$ & $5,07 \pm 3,6(5)$ & $503,45 \pm 693,73(189,2)$ \\
\hline Non-Physician & $1,28 \pm 0,22(1,3)$ & $1,21 \pm 0,36(1)$ & $1,76 \pm 0,44(2)$ & $2,06 \pm 1,2(2)$ & $400,89 \pm 748,02(194,5)$ \\
\hline Physician & $1,76 \pm 0,8(1,4)$ & $1,53 \pm 0,54(1,5)$ & $2,47 \pm 1,01(2)$ & $6,53 \pm 5,85(4)$ & $192,3 \pm 211,62(147,5)$ \\
\hline Trainer & $1,22 \pm 0,15(1,3)$ & $1,33 \pm 0,29(1,5)$ & $1,67 \pm 0,58(2)$ & $1,33 \pm 0,58(1)$ & $22045,57 \pm 37962,62(166,8)$ \\
\hline $\mathrm{P}$ & $0,031^{*}$ & 0,196 & $0,021^{*}$ & $0,014^{*}$ & 0,373 \\
\hline
\end{tabular}

Kruskal Wallis Test ${ }^{*} p<0.05$ Since "Patient" source is $n=1$, it has been excluded from the analysis.

Table V: Evaluation of scores by content

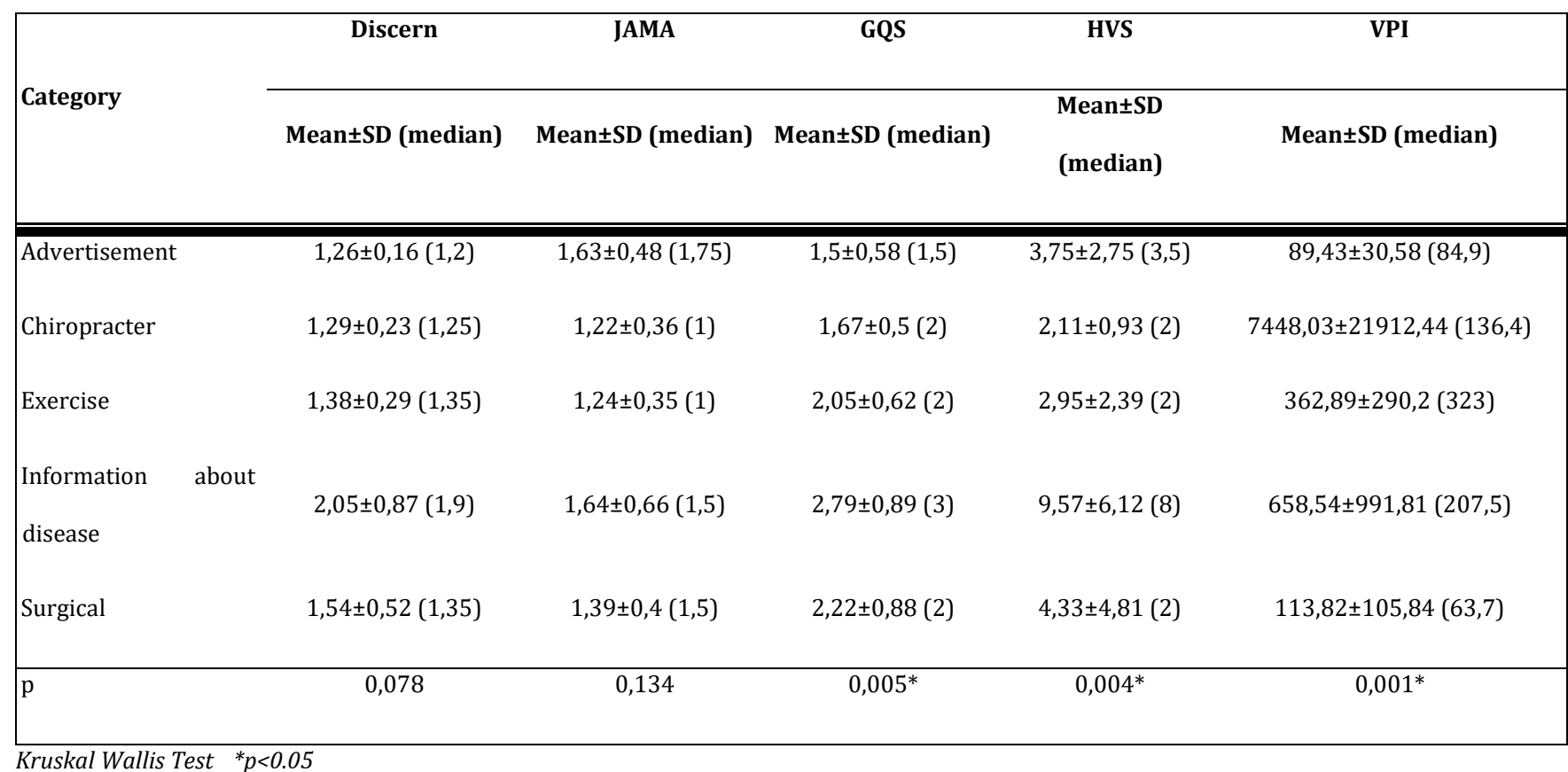

A statistically significant difference was between determine from which contents the significance the GQS scores for content (p: 0.005; $\mathrm{p}<0.05$ ) originated, the GQS score for disease information (Table 5). As a result of the post hoc evaluations to was significantly higher than those for the 
advertisement and chiropractor categories (p1: 0.040; p2: 0.011; p <0.05). No significant difference was between the GQS scores for the other content categories ( $\mathrm{p}>0.05)$.

For the first observer, the JAMA scores varied between 1 and 3 , with a mean of $1.34 \pm 0.54$ and a median of 1 . For the second observer, the JAMA scores ranged between 1 and 3, with a mean of $1.44 \pm 0.56$ and a median of 1 . The average JAMA score was $1.39 \pm 0.48$, and the median was 1.5 (Table 2). The level of agreement between the two observers was 79.1\% (Table 3). There was no statistically significant difference between the JAMA scores for the source ( $p>0.05)$ (Table 4). No statistically significant difference was between the JAMA scores in terms of content ( $p>0.05$ ) (Table 5).

The HVS scores reflected the videos' relevance to hallux valgus in a range from 1 to 20 , with a mean of $4.72 \pm 4.83$ and a median of 2 . A statistically significant difference was found between the HVS scores for the source (p: 0.014; $\mathrm{p}<0.05$ ) (Table 4). As a result of the post hoc evaluations to determine the sources of significance, the HVS score for the nonphysician source was significantly lower than those for academic, medical and physician sources (p1: 0.011; p2: 0.021; p3: 0.006; p $<0.05)$. The HVS score of the trainer resource was significantly lower than those for academic, medical, and physician sources (p1: 0.022; p2: 0.041; p3: 0.024; p <0.05). No significant difference was found between the HVS scores for other sources ( $p>0.05)$. A statistically significant difference was found between the HVS scores for contents ( $p$ : 0.004; p <0.05) (Table 5). Based on the post hoc evaluations to determine categories from which the significance originated, the HVS score for disease information was significantly higher than those for the chiropractor and exercise categories (p1: 0.013; p2: 0.006; p <0.05). No significant difference was found between the other HVS scores for contents ( $p>0.05$ ).

\section{DISCUSSION}

Our hypothesis in the present study is that the content on Youtube related to hallux valgus is not of sufficient quality at the stage of diagnosis and treatment for patients. The primary reason for presenting this hypothesis in this study was that the number of patients searching the internet and, as a result, applying to our outpatient clinic significantly increased. One of the common types of search methods is searching the image. Since there was an easy access to information, YouTube is a social network that attracts people's attention ${ }^{19}$. Since YouTube is a platform not peer-reviewed, patients and physicians should know the different sources of health information and the information variable quality. The YouTube platform can have an impact on patients' diagnosis and treatment of healthcare problems. In other words, misleading or low quality information on YouTube can adversely affect both practitioners and patients ${ }^{20}$. The trend for patients and medical educators to turn to YouTube to learn and teach medical conditions is increasing. On the other hand, the correlation between the content quality and patient involvement has not been proven ${ }^{19}$. The recent increase in the number of studies examining YouTube content quality has a limited effect on orthopaedics, and only a few orthopaedic procedures or diagnoses are studied.

This is the first study which evaluates the quality, usability, and accuracy of hallux valgusspecific YouTube videos. In this study, we found that YouTube videos containing the words "hallux valgus" and "bunion" were of low quality based on Discern, GQS, JAMA and HVS scores. Previous research suggests that low-quality medical information obtained on YouTube harms the relationship between a doctor and his/her patients ${ }^{20}$. Based on many publications 
evaluating the quality of videos on various orthopaedic diseases, we concluded that the videos' accuracy and quality were low ${ }^{21-27}$.

Desai et al. stated that despite the accurate and reliable information offered by the academic videos, the lowest number of users preferred YouTube. Furthermore, they suggested that educational videos are viewed less than videos of low quality ${ }^{19}$. When the sources of the videos evaluated in this study were examined, we found that the Discern, GQS, JAMA and HVS scores for the academic and physician-sourced videos were higher than other sources. We found that VPI was higher in the trainer category, although we did not see a significant difference. Similarly, when the video categories were evaluated, the VPI of the surgical videos was found to be significantly lower than the other categories. However, the Discern, GQS, JAMA and HVS scores for the videos in the category of disease information were higher than those for the other video categories.

In this study, when the relationship between the Discern, GQS, JAMA and HVS scores were evaluated, there was a positive and significant relationship between them (Table 6, Figures 4 and 5). This relationship ultimately demonstrated that the scoring used for hallux valgus was directly proportional to the video's quality and the issues a video should cover when providing information about hallux valgus (Table 6).

Table VI: Evaluation of correlation between Discern, JAMA, GQS, HVS and VPI scores

\begin{tabular}{|c|c|c|c|c|c|}
\hline & & Discern score & Jama score & GQS & HVS \\
\hline \multirow[t]{2}{*}{ Jama score } & r & 0,418 & - & - & - \\
\hline & $\mathrm{p}$ & $0,001^{*}$ & - & - & - \\
\hline \multirow[t]{2}{*}{ GQS } & $\mathrm{r}$ & 0,741 & 0,422 & - & - \\
\hline & $\mathrm{p}$ & $0,000^{*}$ & $0,001^{*}$ & - & - \\
\hline \multirow[t]{2}{*}{ HVS } & $\mathrm{r}$ & 0,700 & 0,438 & 0,721 & - \\
\hline & $\mathrm{p}$ & $0,000^{*}$ & $0,000^{*}$ & $0,000^{*}$ & - \\
\hline \multirow[t]{2}{*}{ VPI } & $\mathrm{r}$ & 0,025 & $-0,081$ & $-0,002$ & 0,072 \\
\hline & $\mathrm{p}$ & 0,842 & 0,524 & 0,985 & 0,574 \\
\hline
\end{tabular}

Spearman Rho Correlation Analysis ${ }^{*} p<0.05$

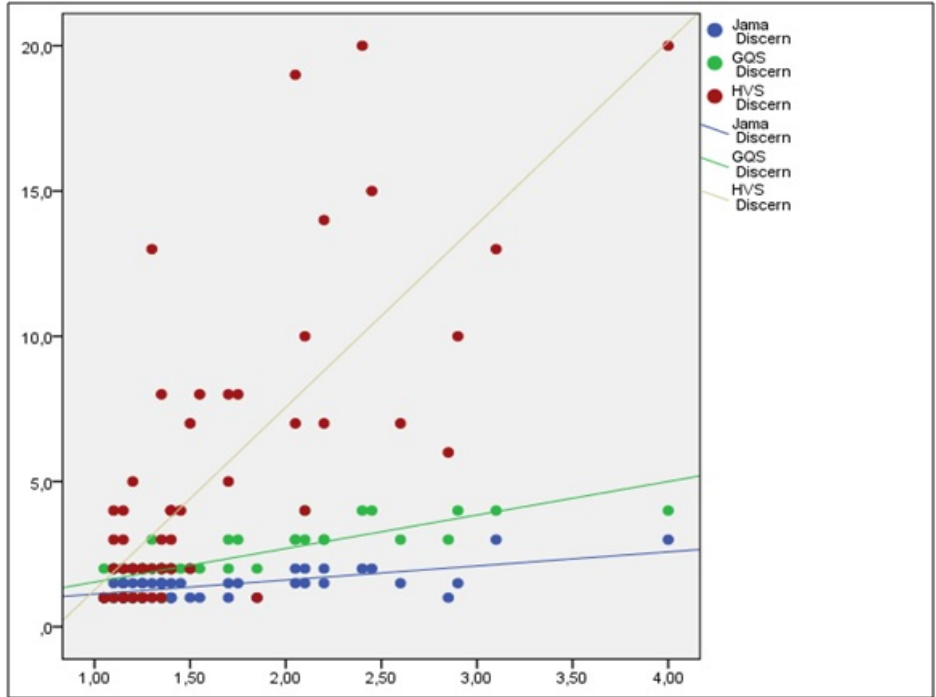

Figure 4: Distribution of Discern score with respect to other scores

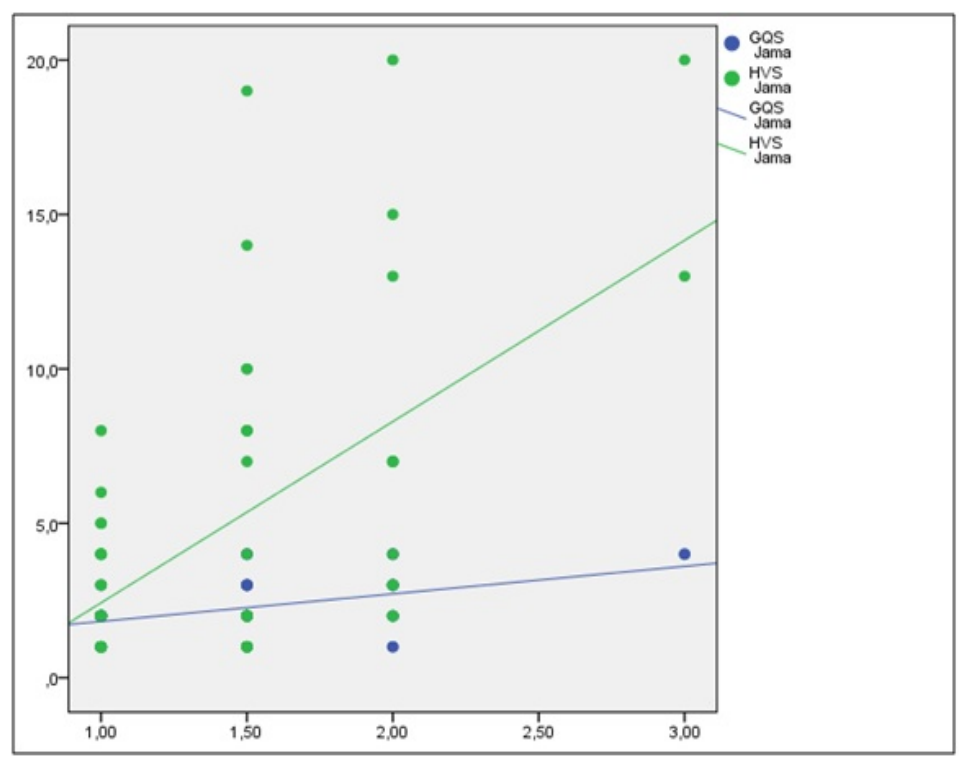

Figure 5: Distribution of JAMA score with respect to other scores

There were several limitations to our study. The 50 videos most frequently viewed when the keywords "hallux valgus" and "bunion" were searched on YouTube were included in the study. While this may appear to be a significant limitation, this study's purpose was to analyse analyze the most-viewed videos on for information from the researcher's perspective, not evaluate all the information which was provided on YouTube about hallux valgus. Most 
of the internet users view only with the first two pages of search results ${ }^{28}$. Thus, only the top listed 50 videos were included in the study.

Second, YouTube as a dynamic sharing platform is built on a search algorithm that can show geolocational patterns; there may be gradual change in the search results due to the increasing number of videos. In this study, no anonymous search was conducted to prevent the effect of geolocation and browsing history. In addition, due to capturing of these data on a single day, it gives only a snapshot of the information accessible at a specific time. The internet is a common source of information through which individuals can constantly remove media from or upload it on open source forums such as YouTube leading to flow of quality and quantity and continual ebb29,30.

Third, only videos accessed directly on YouTube in response to the keywords "hallux valgus" and "bunion" were included in the study. Access to other medical websites via external links were not included in our analysis.

Patients should be directed to video sites easily accessible, do not overwhelm the user with medical terminology, and provide accurate and reliable medical information to their users, without misleading information and commercial abuse. Our results show that even there are inadequate physicians' videos in terms of quality and teaching. Therefore, trusted health organisations organizations and professional associations should provide educational videos that meet all JAMA criteria for the relevant disease, have Discern and GQS scores of 4 above, and do not adversely impact the relationship between clinician and patient.

These videos essentially contain accurate, sufficient, and understandable information on the pathophysiology, natural course, aetiology etiologyw2, and treatment alternatives for the disease, and potential complications and results. One should translate the content into the target country's language, and the physicians informed about those websites. If necessary, they should be reviewed by professionals on the subject and then presented to the patients. Clinicians should direct patients to the appropriate websites and help prepare and promote optimal medical videos. They are aware of the difficulties of treating self-taught patients.

\section{CONCLUSIONS}

Medicine is a science that has been in constant contact with people from the beginning of history to the present, regardless of its subject. YouTube is an essential source of information used by the hallux valgus cohort; however, the quality of the information presented is often low. We believe that the accuracy and quality of the information gained from our social media platform had the opportunity to review and evaluate is crucial for society's health. Orthopaedic physicians should be prepared to alleviate fears or misunderstandings arising from any misinformation and recommend more qualified and scientifically-approved videos. Finally, we should remember that doctors' recommendations on accurate, quality information sources to patients will increase doctor-patient trust; minimize the need to counter misleading or incorrect information during treatment

Ethics Committee Approval: Ethics committee approval was not obtained because our article does not have any human and animal studies, and it is a study evaluating the information given by the public youtube channel on hallux valgus disease.

Declaration of Conflicting Interests: The authors declare that they have no conflict of interest.

Financial Disclosure: No financial support was received. 


\section{REFERENCES}

1.

No

Title,

https://www.internetworldstats.com/stats.htm.

2. Torun E, Guler S, Kucukkoc M. et al. The effects of internet use intensity on quality of life, anxiety and depression scores in pediatric migraine İnternet kullanım sıklığının migrenli çocuk hastalarda yaşam kalitesi, anksiyete ve depresyon skorları üzerine etkileri. Dicle Med J 2014; 41: 23-8.

3. Anderson M. 5 facts about online video, for YouTube's 10th birthday. Pew Research Center.

4. Statistics. Y. No Title.

5. Alexa. Top 500 Global Sites. https://www.alexa.com.

6. Kunst H, Groot D, Latthe PM, et al. Accuracy of information on apparently credible websites: Survey of five common health topics. Br Med J. Epub ahead of print 2002. DOI: 10.1136/bmj.324.7337.581.

7. Joseph A. Diaz MD, Rebecca A. Griffith MD, James J. Ng MD, Steven E. Reinert MS, Peter D. Friedmann MD M\& AWMM. Patients' use of the internet for medical information. J Gen Intern Med 2002; 180-5.

8. John Tristan Cassidy JFB. Orthopaedic Patient Information on the World Wide Web: An Essential Review. J Bone Jt Surg Am 2016; 98: 325-38.

9. Mann RA, Coughlin MJ. Hallux Valgus - Etiology, anatomy, treatment and surgical considerations. Clin Orthop Relat Res. Epub ahead of print 1981. DOI: 10.1097/00003086-198106000-00008.

10. Coughlin MJ, Jones CP. Hallux valgus: Demographics, etiology, and radiographic assessment. Foot Ankle Int. Epub ahead of print 2007. DOI: 10.3113/FAI.2007.0759.

11. Saragas NP, Becker PJ. Comparative Radiographic Analysis of Parameters in Feet With and Without Hallux Valgus. Foot Ankle Int. Epub ahead of print $1995 . \quad$ DOI: 10.1177/107110079501600306.

12. Roddy E. Epidemiology and impact of hallux valgus: more than just bunions. J Foot Ankle Res. Epub ahead of print 2011. DOI: 10.1186/17571146-4-s1-a8.
13. Jansen BJ, Spink A. An analysis of web documents retrieved and viewed. In: Proceedings of the International Conference on Internet Computing. 2003.

14. Singh AG, Singh S, Singh PP. YouTube for information on rheumatoid arthritis - A wakeup call? J Rheumatol. Epub ahead of print 2012. DOI: 10.3899/jrheum.111114.

15. Bernard A, Langille $M$, Hughes $S$, et al. A systematic review of patient inflammatory bowel disease information resources on the world wide web. Am J Gastroenterol. Epub ahead of print 2007. DOI: $10.1111 / \mathrm{j} .1572-0241.2007 .01325 . x$.

16. Silberg WM, Lundberg GD, Musacchio RA. Assessing, Controlling, and Assuring the Quality of Medical Information on the Internet: Caveant Lector et Viewor - Let the Reader and Viewer Beware. Generations. Epub ahead of print 1997. DOI: 10.1001/jama.1997.03540390074039.

17. Tartaglione JP, Rosenbaum AJ, Abousayed M, et al. Evaluating the Quality, Accuracy, and Readability of Online Resources Pertaining to Hallux Valgus. Foot Ankle Spec. Epub ahead of print 2016. DOI: $10.1177 / 1938640015592840$.

18. Charnock D, Shepperd S, Needham G, et al. DISCERN: An instrument for judging the quality of written consumer health information on treatment choices. J Epidemiol Community Health. Epub ahead of print 1999. DOI: 10.1136/jech.53.2.105.

19. T. D, A. S, V. D, et al. Is content really king? An objective analysis of the public's response to medical videos on YouTube. PLoS One.

20. Madathil KC, Rivera-Rodriguez AJ, Greenstein JS, et al. Healthcare information on YouTube: A systematic review. Health Informatics Journal. Epub ahead of print 2015. DOI: $10.1177 / 1460458213512220$.

21. Yadav AK, Prasanna Kumar GS, Khanna V. YouTube - An unreliable source of information for Total hip replacement. J Clin Orthop Trauma. Epub ahead of print 2020. DOI: 10.1016/j.jcot.2020.08.010.

22. Koller U, Waldstein W, Schatz KD, et al. YouTube provides irrelevant information for the diagnosis and treatment of hip arthritis. Int Orthop. Epub 
ahead of print 2016. DOI: $10.1007 /$ s00264-0163174-7.

23. Macleod MG, Hoppe DJ, Simunovic N, et al. YouTube as an information source for femoroacetabular impingement: A systematic review of video content. Arthroscopy - Journal of Arthroscopic and Related Surgery. Epub ahead of print 2015. DOI: 10.1016/j.arthro.2014.06.009.

24. Grassi A, Smiley SP, Roberti di Sarsina T, et al. Mechanisms and situations of anterior cruciate ligament injuries in professional male soccer players: a YouTube-based video analysis. Eur J Orthop Surg Traumatol. Epub ahead of print 2017. DOI: $10.1007 / \mathrm{s} 00590-017-1905-0$.

25. Erdem MN, Karaca S. Evaluating the accuracy and quality of the information in kyphosis videos shared on youtube. Spine (Phila Pa 1976). Epub ahead of print 2018. DOI: 10.1097/BRS.0000000000002691.

26. Akpolat AO, Kurdal DP. Is quality of YouTube content on Bankart lesion and its surgical treatment adequate? J Orthop Surg Res. Epub ahead of print 2020. DOI: 10.1186/s13018-020-01590-0.
27. Cassidy JT, Fitzgerald E, Cassidy ES, et al. YouTube provides poor information regarding anterior cruciate ligament injury and reconstruction. Knee Surgery, Sport Traumatol Arthrosc. Epub ahead of print 2018. DOI: 10.1007/s00167-017-4514-x.

28. Morahan-Martin JM. How internet users find, evaluate, and use online health information: A crosscultural review. Cyberpsychology and Behavior. Epub ahead of print 2004. DOI: 10.1089/cpb.2004.7.497.

29. Elhassan Y, Sheridan G, Nassiri M, et al. Discectomy-related information on the internet: Does the quality follow the surge? Spine (Phila Pa 1976). Epub ahead of print 2015. DOI: 10.1097/BRS.0000000000000689.

30. Nason GJ, Baker JF, Byrne DP, et al. Scoliosisspecific information on the Internet: Has the 'information highway' led to better information provision? Spine (Phila Pa 1976). Epub ahead of print 2012. DOI: 10.1097/BRS.0b013e31826619b5. 